\title{
An Anthology of the Challenges of Beginning Teacher: A Phenomenological Study
}

\author{
Cincy Merly B. Gecolea, Ed.D ${ }^{\mathrm{a}}$, Lerma P. Buenvinida, Ed.D ${ }^{\mathrm{b}}$ \\ a cincymerly.gecolea@deped.gov.ph, ${ }^{\mathrm{b}}$ lermabuenvinida@lspu.edu.ph \\ ${ }^{a}$ Calamba Bayside Integrated School, Brgy.Palingon, Calamba City, Laguna, Philippines \\ ${ }^{b}$ Laguna State Polytechnic University- Los Ban̆os Campus, Laguna, Philippines
}

\begin{abstract}
The study mainly focused on the challenges beginning teachers face when they enter the field of education. It utilized the qualitative research with hermeneutic phenomenology as an approach. Using reflective journal and focus group discussion, beginning teachers' personal reflections of experience were recorded and analyzed to distinguish the most challenging experiences among beginning teachers. Participants of this study were the 21 purposively chosen teachers from the City Schools Divisions of Calamba, Cabuyao, Binan and Sta. Rosa. In this study, the experiences of chosen participants in their first 3 years of teaching were analyzed. Results of the study revealed that the participants are all Education course graduate but most of them does not prefer this course. Meanwhile, the most challenging experiences of beginning teachers include student's diversity, stupefied with works, dissension with colleagues and competencies mismatch. It is recommended that there must be a localized and school-based comprehensive training program aside from the Teachers Induction Program offered for the beginning teachers.
\end{abstract}

Keywords: anthology; beginning teachers; challenges; personal reflections

\section{Introduction}

Education, particularly the role of a classroom teacher, presents a unique set of challenges not encountered in other professions. While most teachers enter the field with the knowledge that their pay will be lower than that of many other professions, still they go on in the teaching profession. It may be because of various personal reasons. Perhaps the overarching appeal is to provide support to young learners; however, the challenges associated with providing support to learners with diverse personality, insufficient classroom management training, and dealing with the unrealized expectations of the teaching profession frequently result in a desire to leave the field of education (Brubaker, 2016).

As the demand for qualified teachers increases across the country, the Department of Education (DepEd), in DepEd Order No. 7, section 2015, states that the success of any educational system depends on its teachers' competence. As a result, one of the primary issues that the Department seeks to address through the comprehensive implementation of the $\mathrm{K}$ to 12 Basic Education Program is the critical shortage of highly qualified teachers in public elementary and secondary schools. The program intends to accomplish this goal by significantly improving professional standards, which will ensure that teachers hired can make a 
significant contribution to the development of lifelong learners. Beginning teachers have been through a selection process and have passed through the various stages of the hiring process. These educators are expected to possess the necessary skills and abilities to provide a high-quality education. The expectations for beginning teachers are high, as they are hired using a new set of hiring guidelines.

Additionally, through various initiatives, the Philippine government has consistently pursued reforms aimed at improving teacher quality. Through CHED Memorandum Order No. 52, section 2007, and DepEd Order No. 32, 2009, the National Competency-Based Teacher Standards (NCBTS) were institutionalized as a framework for teacher quality. It was created as part of the Basic Education Sector Reform Agenda (BESRA). It was made possible using learning perspectives from programs such as the Basic Education Assistance for Mindanao (BEAM), the Strengthening Visayas Education (STRIVE) project, and the Third Elementary Education Project (TEEP). The Department of Education is currently adapting the Philippine Professional Standards for Teachers (PPST).

While numerous research studies have been conducted on the reasons why teachers leave education, there is a dearth of research on the problematic experiences of beginning teachers as told through reflection, and there are also few educational researchers who have examined the difficulties faced by newly hired teachers in the Department of Education. The purpose of this qualitative phenomenological study is to examine the most difficult experiences encountered by beginning teachers and the effect these difficulties may have on beginning teachers' commitment to keep their passion in the teaching profession. This research will examine teachers' lived experiences with the difficulties they encountered during their first to third years in the profession and explain their coping mechanisms. This study will shed light on the difficulties encountered by beginning teachers. This investigation will concentrate on actual, day-to-day interactions and teachers' personal perceptions of their experiences.

\section{Research Questions}

The study looked into the challenges encountered by the public secondary beginning teachers and how they deal or overcome it. Through the results of the present study, the researcher also crafted manual about Comprehensive Training Program for beginning teachers. The central question of the study is:

What is the essence of the lived experiences of public secondary beginning teachers?

Specific Questions

1. How do the teachers describe their lived experiences as regards to the challenges in teaching?

2. What themes emerge from the testimonies shared by the beginning teachers as to the challenges they encounter in teaching?

3. Based on the findings and reflections, what comprehensive training program can be offered to help the beginning teacher? 


\section{Methodology}

This part presents the descriptions of research methodology including research design, population and sampling, respondents of the study, research instrument, data-gathering procedure, ethical considerations, and treatment of qualitative data.

\subsection{Research Design}

The study employed a qualitative approach guided by hermeneutic phenomenology. This method is used when a researcher is "interested in elucidating relationships and patterns within gathered data in order to gain a more complete understanding of a phenomenon" (Research in Daily Life 1, 2016).

The researcher conducted an in-depth examination of the difficulties encountered by beginning teachers. It prompted the researcher to employ this research design, which applies to studying an anthology of beginning teacher challenges.

\subsection{Participants of the Study}

The current study necessitated the recruitment of a relatively homogeneous group of participants.

The participants in this study were twenty-one (21) beginning teachers, all of whom were female and were in their first three years of teaching in public schools. Although thirty teachers were initially interviewed regarding their willingness to participate in the study, nine teachers did not meet the researcher's set criteria and were not interviewed during the focus group discussion. Consent letters were sent to the selected beginning teachers.

\subsection{Research Instrument}

The researcher gathered pertinent information by directing the flow of discussions with respondents using interview guide questions. For the respondents, the researcher prepared fifteen questions. These questions elicited reflections on the entire discussion and then solicited participants' positions or opinions on issues of critical importance to the researcher. The researcher used open-ended questions, which ensured that participants were engaged. The interview guide questions aided in gaining a better understanding of the difficulties faced by beginning teachers. The interview guide questions were validated by ten experts, all of whom hold doctorates and have experience conducting qualitative research.

\subsection{Data Gathering}

A letter of consent was obtained from the Superintendents of the Schools Divisions of Cabuyao, Sta Rosa, Biňan, and Calamba City. Additionally, a letter of consent was sent to the School Heads of each division's schools. Following that, a Focus Group Discussion with the teachers was scheduled. Before facilitating the interview, the researcher prepared guide questions, recording devices, and writing materials. Additionally, an assistant was requested to participate to transcribe the discussion. Transcripts of the recorded interviews were compared to the written account. Following that, she encoded the verbatim transcription, tabulated the data, and analyzed the qualitative data to identify emerging themes. 
Additionally, in this phenomenological study, the primary data collection method is in-depth interviews with participants (Creswell, 2007). Similarly, multiple interviews with each of the research respondents were conducted (Creswell, 2007). Focus group interviews, observations, and video recordings were used to collect data. In addition to the interview, the research environment was observed using an observation method. Data were gathered from a variety of informants to facilitate triangulation.

\subsection{Treatment of Qualitative Data}

This study used a qualitative method known as theme-centered or category-based analysis. Thematic analysis is a term that refers to analysis that is focused on a specific theme. Thematic analysis is accomplished using data coding. Coding is accomplished by combining data for themes, ideas, and categories and labeling similar text passages with a code label so they can be retrieved and compared at a later stage. Coding the data simplifies the process of searching for, comparing, and identifying any pattern (Alase, 2016). Additionally, the data analysis for this phenomenological study was conducted using Giorgi's descriptive phenomenological method (1989).

\subsection{Trustworthiness}

To assure the readers that the findings are worth paying attention to, the researcher established the study's credibility by presenting significant findings based on a viable research design. The study's participants and setting are relevant to the research design.

The validity, reliability, and triangulation of data all contribute to the research's credibility (Patton, 1999). Each of the aforementioned factors aided the researcher in accurately describing the real world or reality discovered during this research project. Among the elements that contribute to credibility, triangulation succinctly contributed to the development and maintenance of the validity and reliability of the abundant data gleaned.

Data triangulation, member verification, extensive description, theoretical sampling, peer debriefing, and auditing are just a few of the techniques used to ensure trustworthiness.

\section{Results}

This part presents the analysis and interpretation of the data gathered in this study. The intention of this phenomenological study was to look into the challenges encountered by the public secondary beginning teachers and how they deal or overcome it. The researcher began with gathering information regarding participants' ideas and reflections regarding the challenges they encountered.

\subsection{How do the teachers describe their lived experiences as regards to the challenges in teaching?}

The testimonies of the participants revealed that the challenges encountered by beginning teachers are students' behavior and attitude, workload issues, subject mismatch and co-teachers' attitude and personalities.

Students' behavior and attitude were among the stiff challenges experienced and shared by most research participants. 
In addition, another challenge encountered by beginning teachers is workload issues. Several participants shared their experiences regarding how they encountered difficulty in making several reports and documents to be submitted which is far behind their expectations. T4 shared her experience during her first year as a public-school teacher. Prior to her entry in public school, she was first a senior high school public teacher and never experience doing several reports.

Another participant shared her experience how she was over-whelmed by the overloaded works needed to be done by a public-school teacher. T13 is a computer teacher who handled several subjects and sections.

Further, the beginning teachers encountered challenges due to subject mismatch. These participants are handling subjects which are not their specialization during their bachelor's degree.

Lastly, the participants also encountered difficulty in terms of co-teacher's attitude and personalities. These participants shared their unforgettable experience with regards to their relationship with their colleagues. One of the participants who narrated her story is T2, a Filipino teacher who teaches first in a wellknown school before she applied in public school.

Even though the participants encountered different challenges, majority of the participants expressed that they were not able to receive any tangible support program from the school or from their own department. The kind of support they received is just by assigning them to more experienced teachers who can assist them while they are adjusting.

The testimonies of the participants were categorized into fair distribution of task, seminar on teaching strategies, teachers' proper orientation and stress management.

Moreover, the annotated exemplars of the participants with regards to the advice that they can share to other beginning teachers to cope-up and survive the midst of the challenges they encounter. Based on the testimonies of the participants, their advice to other beginning teachers who want to succeed in this field of work can be sum-up to "don't give-up", "be tough" and "be positive".

Majority of the participants responded that the best way to be successful in the field of teaching is not by quitting in the profession whenever you encounter difficulty.

3.2 What themes emerge from the testimonies shared by the beginning teachers as to the challenges they encounter in teaching?

\section{Student Diversity}

The themes that emerged from the testimonies of the participants were clustered into superordinate theme: student diversity while the subordinate themes are students' behavior, students' attitude, and students' personalities.

This theme does not only cause disadvantage to the teachers, but it will also help beginning teachers to be fully equipped with necessary techniques about classroom management. Teachers must need to understand diversity among students because it is part of student's development. 


\section{Stupefied of works}

The second theme emerged from the testimonies of the participants are workload issues by which they are stupefied with works. Its subordinate themes are overloaded works, overwhelming workloads, and loaded subjects.

All the research participants in this study shared experiences in which they were left with a sense of disenchantment and disappointment with their chosen field.

\section{Dissension with colleagues}

The third theme emerge is dissension with colleagues and its subordinate themes are co-teachers' attitude, different teachers' personalities and gossip teachers. It has something to do with social challenges encountered by beginning teachers which is about dissension between colleagues. Conflict is a reality of working with others.

\section{Competencies incongruity}

The final theme that emerged from the testimonies of the participants is about skills and competencies incongruity which may be attributed to subject mismatch. Competencies mismatch may cause discouragement among teachers because they will not be confident to teach and impart knowledge and ideas to their students because they personally lack necessary information to teach the subject assigned to them. Even though teachers are flexible, it is also important to consider their field of specialization.

3.3 Based on the findings and reflections, what comprehensive training program can be offered in order to help the beginning teacher?

The study necessitates an action plan based on the findings of the study focusing on the support programs that the participant wants to receive and be given to the upcoming beginning teachers. This comprehensive training program manual will provide localized guide for each school regarding school-based training that can be given for beginning teachers to adjust in their first to three years in the service.

\section{Discussion}

The study revealed that majority of the participants are graduates of Education course, but it is not their preference or first choice. There are so many reasons why they choose to be a teacher, but the most prevailing reason is that their preferred course is not affordable. There are also participants who chose this profession because it is their dream to be a teacher and impart knowledge for the students. The participants had their in-campus and off-campus practice teaching. Some of them were not able to attend the Teachers induction program given by the Department of Education.

It also shows that the beginning teachers face the following challenges: (a) student diversity, (b) stupefied with work, (c) dissension with colleagues and (d) skills and competencies incongruity. Despite the challenges encountered by these teachers they were able to handle and cope-up with these difficulties because of the support given by the school by assigning them to a more experienced teachers who can assist them. 


\section{Recommendations}

The following recommendations are made based on the findings of the study:

1. The Department of Education may review their guidelines for selecting and hiring new teachers to ensure that those wishing to enter the profession are fully equipped with the skills of seeking answers to complex problems of teaching and learning, rather than simply relying on their undergraduate credentials, as is currently the case.

2. To assist beginning teachers in recognizing and building on the knowledge and experience they bring into the classroom; the school head may develop an effective plan that assists the teachers in gaining what is weak or lacking and extends learning so that the teacher progresses to higher levels of accomplished teaching.

3. The comprehensive training program manual, which highlights the proper way of orienting beginning teachers to help them fully adjust during their first three years of service, may be considered by school officials in the future.

4. Future researchers may conduct a phenomenological study with a methodology like the current study but with a variation in the participation of candidates based on their gender and geographic location.

\section{References}

Bartell, C. A. (2004). Cultivating high-quality teaching through induction and mentoring. Thousand Oaks

Brubaker, Wanda Margarette (2016). A Teacher's Journey: A Phenomenological Analysis of the Lived Experience of Beginning Teachers. Gardner-Webb University

Cassity, Amanda H. (2012). Relationships among Perceptions of Professional Learning Communities, School Academic Optimism, and Student Achievement in Alabama Middle and High Schools

Creswell, J.W. (2007). Qualitative inquiry \& research design: Choosing among five approaches (2nd ed.), Thousand Oaks, CA: Sage.

Darling-Hammond, L., Chung, R., \& Frelow, F. (2002). Variation in teacher preparation how well do different pathways prepare teachers to teach? Journal of teacher education, 53(4), 286-302.

David A. \& Alice Y. Kolb (2017). Experiential Learning Theory as a Guide for Experiential Educators in Higher Education. Experience Based Learning Systems, Inc., ELTHE: A Journal for Engaged Educators

D.O No. 7, s. 2015. Hiring Guidelines for Teacher I Position Effective School Year 2015- 2016 